\title{
Controlling Factors of Batchwise Separation of Hydrocarbons by Liquid Membranes
}

\author{
Satoru Kato and Junjiro Kawasaki
}

\begin{abstract}
Dept. of Chem. Eng., Tokyo Inst. of Tech. Tokyo 152
Key Words : Membrane Separation, Liquid Membrane, Hydrocabon Separation, Membrane Stability, Emulsion

Controlling factors of batchwise separation of hydrocarbons by liquid membranes were derived from the model proposed previously ${ }^{4}$, which predicts hydrocarbon permeation through liquid emulsion membranes. The range of values for the factors were determined from reported experimental data ${ }^{1-4)}$. The present paper further describes effets of factors and initial operating parameters on the relationship between yield and selectivity in hydrocarbon separation.
\end{abstract}

\section{乱流遷移域における夜体混合に及ぼす印加音の影響 ${ }^{\dagger}$}

\section{小川浩平・黒田千秋・広瀬俊樹}

\section{東京工業大学工学部 化学工学科}

化学装置内の流動場の構造を, 外部からなんらかの方 法によって変化させることができれば, 流動場の構造に 強く影響される混合を促進するてとが可能となる。

装置内に直接攪找翼などを挿入することなくその流動 場の構造を変化させる手法の一つとして, 音を印加する ことが考えられる. 従来より流動場と印加音の関係につ いては実験的に研究されてきてはいる ${ }^{1-14)}$. しかしその ほとんどの場合が高周波音を空気に印加しており，低周 波音の印加が液体混合に及ぼす影響についての研究は, 実験的にもほとんどなされていないといってよい。この 問題を理論的に解析するてとは困難であるが, 印加され た音が液体に伝播・散乱・吸収されて圧力変動が生じ, さらに流動場の構造が変化するという因果性は期待でき る.したがって，音を印加するてとにより混合効果を向 上させられる可能性はあると考えられる.

そてで本論文では，印加音の液体混合促進効果を検討 する基礎として, カルマン渦を発生する円柱を流入口に 設置した無擤找流通系円筒槽を用い，槽底部薄膜を通し

\footnotetext{
† 1987年 7 月 30 日受理 ; 化学工学協会第52年会（名古屋, 1987年 4 月）にて発表

H $\mathbf{1 5 2}$ 目黒区大岡山 2-12-1
}

て印加した音が槽内の液体混合に及ぼす影響について， 過渡応答法を用いて実験的検討を行った。

\section{1. 実験装置および方法}

使用した実験装置の概略を Fig. 1 亿示す. 円筒槽はア クリル樹脂製（内径 $50 \mathrm{~mm}$, 高さ $75 \mathrm{~mm}$ ）であり, 底部 より $12 \mathrm{~mm}$ の位置に内径 $5 \mathrm{~mm}$ の円管を流入口, 流出口 として槽軸に対して対称に取り付けた。流入口中央には カルマン渦を発生させるために，外径 $1.45 \mathrm{~mm}$ の円柱を 槽軸に直角に設置した，槽底部は厚さ $0.1 \mathrm{~mm}$ の OHP用 フィルムを張り，その直下 $4 \mathrm{~mm}$ 離して内径 $55 \mathrm{~mm}$ のス ピーカーを取り付けた.

試験液体は槽上方 $1.22 \mathrm{~m}$ のオーバーフロータンクより 流下し，流量調節用バルブを経て流入口より槽内に入り， 流出口より排出される。な拉実験中は槽内の試験流体の 液深を常に $40 \mathrm{~mm}$ 一定に保った。

槽底部の OHP用フィルムを通して槽内に印加する音は， オシレーターにより周波数㧍よび振幅を所定值に設定し て出力した電気信号を, パワーアンプでさらに增幅をし てからスピーカーにより音に変換したあのである.

過渡応答法は, 試験液体として水を流通させ，十分定 常な流動状態に達した時点で, 電磁弁を用いて流入口の 

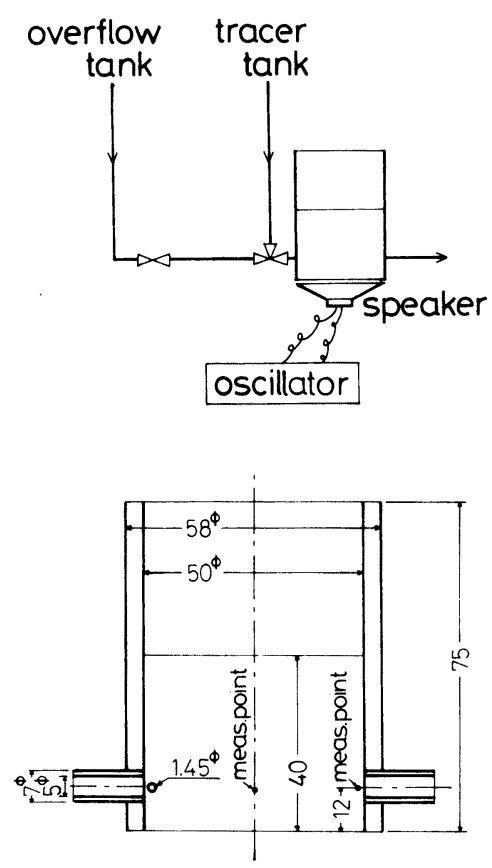

Fig. 1 Experimental apparatus

上流側 $5 \mathrm{~mm}$ に設置したノズルより $1.2 \mathrm{wt} \% \mathrm{KCl}$ 水溶液 をステップ状に注入して行った，注入されたトレーサー の流出口における濃度の経時変化は, 電気伝導度プロー ブ（外径 $0.3 \mathrm{~mm}$, 長さ $1.0 \mathrm{~mm}$ の白金線 2 本を $0.5 \mathrm{~mm}$ 離して設置したもので, 測定精度 $0.1 \mathrm{~mol} / \mathrm{m}^{3}$ 程度, 応答 速度 $100 \mathrm{~Hz}$ 以上）により測定した。 なお電気伝導度プロ 一ブからの出力と KCl 濃度との関係を示す検定線は実験 ごとに求めた.

さらに参考のために, 槽軸上の流出入口と同じ高さで, 流速変動を電極反応流速計 (外径 $0.3 \mathrm{~mm}$, 長さ $0.5 \mathrm{~mm}$ の白金円柱プローブで, 測定精度 $0.1 \mathrm{~cm} / \mathrm{s}$, 応答速度 50 $\mathrm{Hz} \sim 60 \mathrm{~Hz}$ 以上)で, また圧力変動を小型圧力センサー （共和電業製 PML $500 \mathrm{G}$ で，测定精度 $5000 \times 10^{-6}$ 歪， 応答速度数 $\mathrm{kHz}$ ) で測定した。 流速変動を測定する場合 は, $\mathrm{K}_{3} \mathrm{Fe}(\mathrm{CN})_{6}$ と $\mathrm{K}_{4} \mathrm{Fe}(\mathrm{CN})_{6}$ をそれぞれ $1.0 \times 10^{-3} \mathrm{~mol}$ $l l$, および $\mathrm{KCl}$ を $0.1 \mathrm{~mol} / l$ 含む水溶液を用い, 対極の 白金板を底部より $12 \mathrm{~mm}$ の槽内壁面に設置した。な掞同 プローブからの出力と流速との関係を示す検定線は実験 ごとに求めた.

上記いずれのデータも磁気テープに記録し, 電算機を 用いてその解析を行った。

操作変数としては, 発生するカルマン渦の周波数を变 化させることのできる流量と, 印加する音の周波数を選 んだ. 流量は, カルマン渦が安定して発生する範囲と考 えられる $3.5 \mathrm{~cm}^{3} / \mathrm{s} \sim 13.2 \mathrm{~cm}^{3} / \mathrm{s}$ とした. 乙の範囲は，流
Table 1 Experimental conditions

\begin{tabular}{cc}
$N_{K}[\mathrm{~Hz}]$ & $N_{S}[\mathrm{~Hz}]$ \\
25 & 60 \\
35 & $60 \ldots \ldots \ldots \ldots \ldots \ldots \ldots \ldots \ldots \ldots \ldots$ \\
50 & $25,35,50,60,75,85$ \\
60 & $25,35,50,60,75,85$ \\
75 & 60 \\
85 & 60 \\
95 & 95 \\
\hline
\end{tabular}

入管断面平均流速および流入口の円柱外径をそれぞれ代 表速度および代表長さとしたレイノルズ数 Re で 250 1100, またての Re に対応するストロー八ル数により算 出されるカルマン渦の周波数 $N_{K}$ で $25 \mathrm{~Hz} \sim 95 \mathrm{~Hz}$ に相当 する. 印加音の周波数 $N_{S}$ は $N_{K}$ と同一範囲とした．槽内 局所における音の強さをそれぞれ一定に保ちつつ操作変 数を変化させることは困難である。 そこで音のパワーを 一定に保つこととし，すべての実験条件でスピーカー実 効消費電力を $0.18 \mathrm{~W}$ 一定とした。なおての条件下で試験 流体を静止させたときの, 流速変動測定位置における音 の強さは $1.70 \times 10^{-3} \mathrm{~W} / \mathrm{m}^{2} \sim 3.39 \times 10^{-3} \mathrm{~W} / \mathrm{m}^{2}$ の範井であっ た. 以上の範囲で実際に実験を行った操作条件をTable 1 に示す.

\section{2. 実験結果および考察}

過渡応答法の結果の一例として, $N_{K}=50 \mathrm{~Hz}$ の条件で $N_{S}=60 \mathrm{~Hz}$ の音を印加した場合としない場合の流出口に おけるトレーサー濃度の経時変化を比較して Fig. 2 に示 す. 横軸は時間, 縦軸は濃度に対応する出力電圧であり, 応答速度 $20 \mathrm{~Hz}$ 程度のペン書きレコーダーを用いて描い たものである，音を印加するてとによる影響は，平均的 な濃度の経時変化にはみられないが, 濃度変動には振幅 やピーク数の減少としてみられる．乙のような傾向は他 の操作条件に拈いてもみられたが，濃度変動への影響の 程度は $N_{K}$ や $N_{S}$ の值によって異なることが推測された。

なお装置内の流動が原因となる振動・スピーカー稼㗢 による振動・それらに対する装置自体の固有振動などの 機械的振動が及ぼす影響を検討するために, OHP用フィ ルムの代りに厚さ $1.5 \mathrm{~mm}$ のアクリル樹脂製板を用いて 同様の実験を行った。その結果，音を印加しても平均的 な濃度の経時変化にも濃度変動にもその影響はみられな かった. このことは, 上記機械的振動が混合現象に大き な影響を及ぼしていないてとを推測させる。

そこで以下では，上記の平均的な経時変化で示される 程度の混合をマクロ混合, またその平均的な経時変化を 除いた濃度変動で示される数 $10 \mathrm{~Hz}$ 程度の混合をミクロ 混合と呼ぶことにする. 

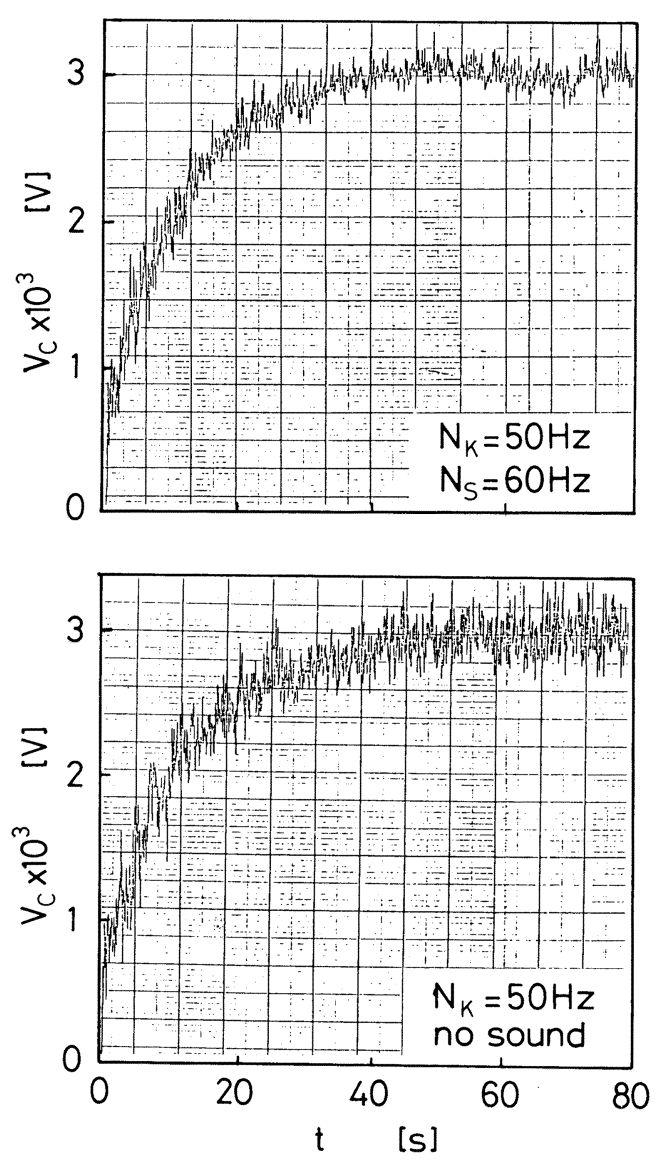

Fig. 2 Data by transient response method

\section{$2 \cdot 1$ マクロ混合に及ぼす印加音の影響}

マクロ混合に及ぼす印加音の影響を定量的に検討する ために，同一操作条件における四回の実験の濃度変動の 経時変化をサンプリング周波数 $16 \mathrm{~Hz}$ でデジタル化し, 32 個のデータでとに移動平均してトレーサーの注入開始 時刻からの平均的な濃度の経時変化を求めた。一例とし て Fig. 2 と同一操作条件での結果を Fig. 3 亿示す. 横軸 は時間, 縦軸は定常状態平均濃度で無次元化した濃度で ある．先に推測したように音を印加したてとによる影響 は特に認められず，音を印加した場合もしない場合む図 中に示した実験式で平均的な経時変化は表される．乙の 傾向は他の操作条件でも同様にみられた。このことから, 槽内のマクロ混合に及ぼす印加音の影響はないてとが明 らかとなった。

\section{$2 \cdot 2$ ミクロ混合に及ぼす印加音の影響}

ミクロ混合に及ぼす印加音の影響を定量的に検討するた めに, 濃度変動強度および濃度スペクトル密度を求めた.

1）濃度変動強度同一操作条件に打ける四回の実 験の濃度変動の経時変化を, サンプリング周波数 $40 \mathrm{~Hz}$

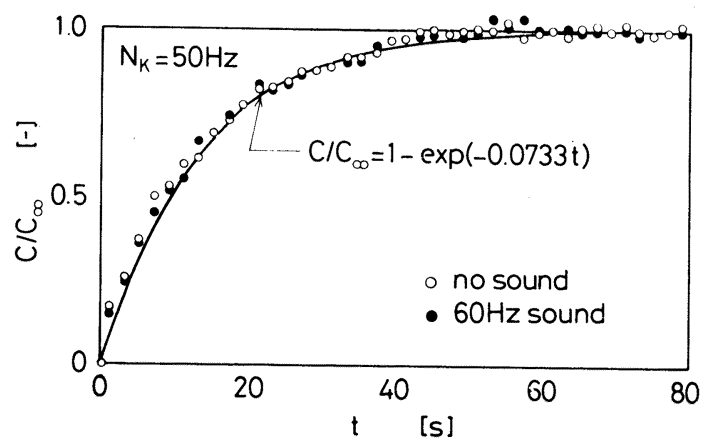

Fig. 3 Change of dimensionless concentration with time

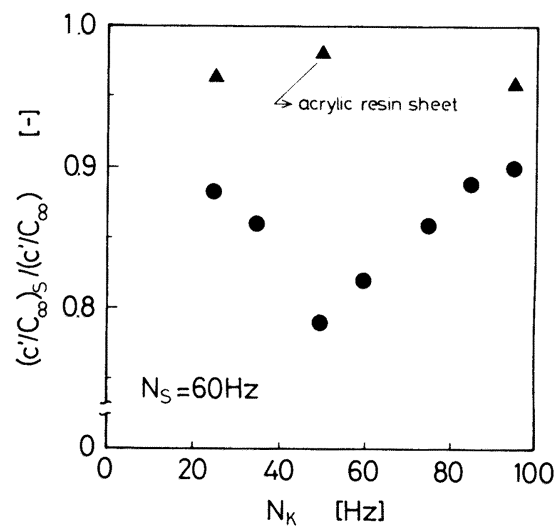

Fig. 4 Effect of applied sound on intensity of concentration fluctuation

で $50 \mathrm{~s}$ 間デジタル採取し, 濃度变動強度を求めた。一例 として $N_{S}=60 \mathrm{~Hz}$ の条件で $N_{K}$ を変化させた場合につい て, 音を印加した場合としない場合の濃度変動強度の比 をFig. 4亿示した。同図は平均的な濃度の経時変化が緩 やかになった無次元濃度が 0.95 以上を示す範囲について の結果である. 印加音の周波数に近い $N_{K} \simeq 50 \mathrm{~Hz}$ に扔い て最小值をとる分布となっている．また同図には前述の 槽自体の機械的振動の影響を検討するために行った実験 結果あ併せて示してある. 印加音の影響が最小となる $N_{K}$ $=95 \mathrm{~Hz}$ において 0.9 , 槽自体の機械的振動の影響が最大 となる $N_{K}=25 \mathrm{~Hz}$ で約 0.96 であるてとから, この濃度 変動強度の比の減少は槽自体の機械的振動による影響が 主たる原因ではないことが確認される.一方, 上記の機 械的振動以外に底部の OHP 用フィルムの機械的振動に よる影響も考えられるが，その影響を分離して評価する ことは困難である.しかし Fig. 4亿示した実験では, 印 加音の周波数は $N_{S}=60 \mathrm{~Hz}$ で一定に保っていることから, 印加音による OHP 用フィルムの強制的振動の影響はす べての $N_{K}$ においてほぼ同じであると考えられる．した 


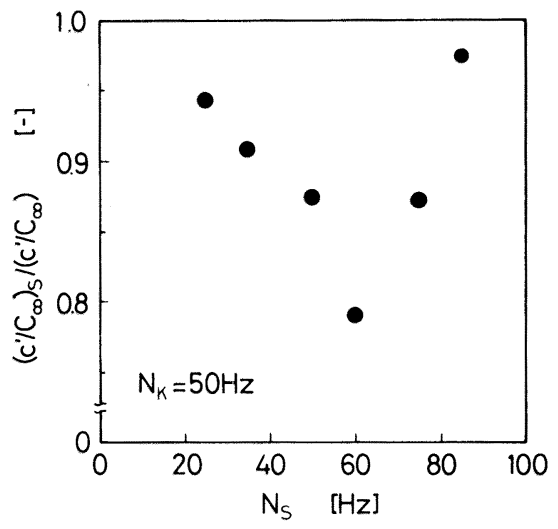

Fig. 5 Effect of Kármán vortex on intensity of concentration fluctuation under applied sound

がって, 例えば $N_{K}=95 \mathrm{~Hz}$ での濃度変動強度の比の減少 がすべて上記機械的振動によるすのと考えたとしてあ， $N_{K}=50 \mathrm{~Hz}$ や $N_{K}=60 \mathrm{~Hz}$ においては純粋に印加音による 濃度変動強度の比の減少が約10\% 15\%認められるととに なる。

Fig. 5 はFig. 4 で最小值を示した $N_{K}=50 \mathrm{~Hz}$ 亿おいて $N_{S}$ を変化させた場合の濃度変動強度の比の結果である。 やはり $N_{S}=60 \mathrm{~Hz}$ で最小値となる分布となっている.

以上から, 音を印加するととにより濃度変動強度の比 の減少，すなわちミクロ混合促進効果が生じるとと，そ の最大の効果は発生したカルマン渦の周波数に近い周波 数の音を印加した場合に得られることが明らかとなった。

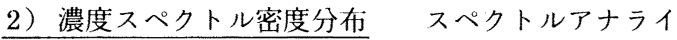
ザー（TEAC製F 150）を用いてサンプリング周波数を $100 \mathrm{~Hz} \sim 300 \mathrm{~Hz}$ 亿種々変化させて濃度スペクトル分布を 求めた。いずれの操作条件に抢いても，音を印加した場 合にも定まった周波数においてピークのないほぼ連続し た分布が得られた，全操作条件の中で最もミクロ混合促 進効果が認められた操作条件 $N_{K}=50 \mathrm{~Hz}, N_{S}=60 \mathrm{~Hz}$ の 濃度スペクトル密度分布を例として Fig. 6 亿示す。音を 印加するてとにより約 $10 \mathrm{~Hz} \sim 20 \mathrm{~Hz}$ の周波数成分のス ペクトル密度の減少が比較的顕著に認められる。乙の結 果は $10 \mathrm{~Hz} \sim 20 \mathrm{~Hz}$ の周波数成分に相当する濃度塊が， 他の周波数成分に相当する濃度塊の場合上り, 上り互い に合一や分裂老繰り返し，より大きい，あるいはより小 さい濃度塊に変化したてとによると考えるてとができる. 同様の結果は他の濃度変動強度の比の減少が大きい操作 条件に打いてあみられた。しかしミクロ混命促進効果が ほとんど認められない操作条件では，各周波数成分のス ペクトル密度には印加音の有無による差異は全く認めら れなかった。

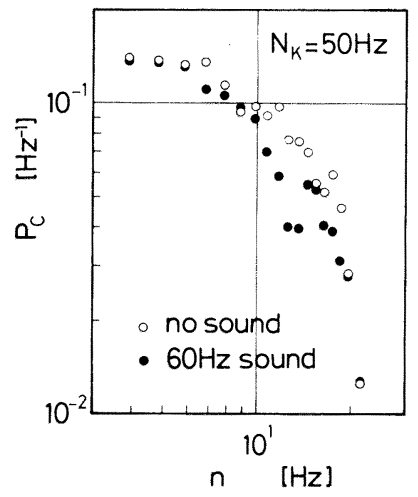

Fig. 6 Comparison of spectrum density distribution of concentration under applied sound with that under no sound

\section{$2 \cdot 3$ 流速変動および圧力変動に及ぼす印加音の影響}

1）流速変動最もミクロ混合促進効果が認められ た操作条件下で乱流強度を求めたところ, 音を印加しな かった場合との差異は認められなかった。

また同じ操作条件下で速度スペクトル密度分布を求め たところ，音を印加した場合にも定まった周波数におい てピークのないほぼ連続した分布が得られた．音を印加 することにより, 濃度スペクトル密度分布で影響がみら れた $10 \mathrm{~Hz} \sim 20 \mathrm{~Hz}$ の变動周波数成分のスペクトル密度 が若干増加していることが認められた。

2) 圧力変動最むミクロ混合促進効果が認められ た操作条件下で圧力スペクトル密度分布を求めたところ, 印加音の周波数と同じ周波数成分のみが非常に大きい線 スペクトルに近い分布が得られた。

\section{Nomenclature}

$C=$ concentration

$[\mathrm{mol} / l]$

$C_{\infty}=$ time-mean concentration at final state on stepwise response

$[\mathrm{mol} / l]$

$c^{\prime}=$ intensity of concentration fluctuation

$[\mathrm{mol} / l]$

$N_{K}=$ frequency of Kármán vortex

$N_{\mathcal{S}}=$ frequency of applied sound

$n$ = frequency

$P_{C}=$ spectrum density of concentration

$\left[\mathrm{Hz}^{-1}\right]$

$R e=$ Reynolds number

$t \quad=$ time

$V_{c}=$ output voltage

\section{Literature cited}

1) Chambers, F.W: and V.W.Goldschmidt: AIAA J., 
20, 797 (1982)

2) idem: AIAA P., 82-0048 (1982)

3) Chanaud, R.C. and A.Powell: J. Acoust. Soc. Am., 34, 907 (1962)

4) Cooper, P.I, J.C. Scherriden and G.J. Flood: Int. J. Heat and Fluid Flow, 7, 61 (1986)

5) Ingard, U. and V.K.Singhal: J. Acoust. Soc. Am., 55, 535 (1974)

6) Itao, F.: Nagare, 1, 360 (1982)

7) Kimura, I. and M.Yonemochi: Keisoku Jidou Seigyo Gakkai Ronbunshu, 14, 196 (1978)

8) idem: ibid., 15, 953 (1979)
9) Kimura, I., S. Nagamine and M.Yonemochi: ibid., 16, 245 (1980)

10) Kimura, I. and M. Yonemochi : ibid., 18, 78 (1982)

11) Kuhn. G.F. and C.L. Morfey: J. Sound and Vib., 44, 525 (1976)

12) Rockwell, D.O. and K.Toda: Trans. ASME, J. Basic Eng., 93. 63 (1971)

13) Roffman, G.L. and K.Toda: Trans. ASME, J. Eng. for Ind., 91, 1161 (1969)

14) Thomas. F.O. and V.W. Goldschmidt: Trans. ASME, J. Fluid Eng., 105 (1983)

\section{Effect of Applied Sound on Mixing of Liquid in Transient State}

\section{Kohei Ogawa, Chiaki Kuroda and Toshiki Hirose}

Dept. of Chem. Eng., Tokyo Inst. of Tech., Tokyo 152

Key Words ; Mixing, Sound, Concentration, Fluctuation, Macro Mixing, Micro Mixing

The effect of applied sound wave passed through the bottom of a cylindrical tank, which has a column of small diameter at the inlet in order to originate the Kármán vortex as a known disturbance and through which liquid flows, was investigated experimentally by injecting a tracer stepwise at the inlet of the tank. It was made clear that a low-frequency sound wave having almost the same frequency as that of the Kármán vortex promotes micro mixing, represented by fluctuations having a lower frequency than that of the Kármán vortex.

正 誤 表 13 巻 4 号 $\sim 6$ 号 (1987)

\begin{tabular}{|c|c|c|c|}
\hline 号 & ページ & 誤 & 正 \\
\hline 4 & 507 実験装置および方法 66 & 非当温 & 非等温 \\
\hline 5 & 650 右 Eq.(16) & $+W$ & $-W$ \\
\hline & 650 右 Eqs.(18),(19) & $\sqrt{-16 i \alpha^{*}}$ & $\sqrt{16 i \alpha^{*}}$ \\
\hline & 650 右 Eqs.(18),(19) & $R e_{L}$ & $9 R e_{L} / 64$ \\
\hline & 650 右 Eqs.(24),(25) & $\left.\times\left(R e_{L} / 4\right)^{-2 / 3}\right]$ & $\left.\times\left(R e_{L} / 4\right)^{-2 / 3} \alpha^{* 2}\right]$ \\
\hline & 651 左 Eq. (28) & $=\mid \alpha^{*} \phi^{*}(1)$ & $=2 \mid \alpha^{*} \phi^{*}(1)$ \\
\hline & 654 左 Fig. 8 & $2 \eta_{0 m}^{*}[-]$ & $2 \eta_{0 m}{ }^{*} \times 10^{3}[-]$ \\
\hline 6 & 833 Nomenclature $\downarrow 3$ & $\begin{array}{c}C \text { の単位 } \\
{\left[\mathrm{h}^{-1}\right]}\end{array}$ & {$\left[\mathrm{m}^{2-2 n} \cdot \mathrm{kg}^{n-1} \cdot \mathrm{h}^{-1}\right]$} \\
\hline
\end{tabular}

